\title{
DEVELOPMENT OF THE PERFORMANCE MANAGEMENT PROCESS BASED ON RISK BREAKDOWN STRUCTURE AT BUSINESS PROCESSES IN THE CENTRAL CITY MIXED-USED REGENERATION
}

\author{
Chang-Teak Hyun*, Myung-Jin Son, RunZhi, Dae-Hyun Kim, and You-Sang Yoon \\ Department of Architecture Engineering, University of Seoul, Seoul, Korea \\ *Corresponding author (cthyun@uos.ac.kr)
}

\begin{abstract}
Recently, CBD(Central Business District) mixed-used regeneration programs(mega-projects) composing various types of residential, commercial, office, and cultural facilities are being promoted to maximize land and space utilization in the inside and outside of the country. It has advantages that meet the functions and the needs of each facility and create new spatial function. On the other hand, several problems are pointed out, such as large project cost, long-term project period and complicated interests among the diverse stakeholders. Especially, CBD mixed-used regeneration is influenced in numerous risks from the early stage of the project, such as land utilization restriction, approval delay, conflicts with surrounding area and traffic impact assessment. Nevertheless, failure cases of projects are being increased, since the studies on the program processes, the parties participating in the project, and the risk factors related to the large-scale CBD mixed-used regeneration are not sufficient. Therefore, this study aims to develop a risk breakdown structure based on business processes and develop a three-dimensional performance measurement method in connection to the structure, and ultimately provide a risk management process appropriate for large-scale projects.
\end{abstract}

Keywords: CBD Mixed-used Regeneration, Risk Breakdown Structure, Risk \& Performance Measurement, Threedimensional Area Measurement Method

\section{INTRODUCTION}

CBD mixed-used regeneration programs(mega-projects), which maximize use of space on a limited site and organically connect residential, office, commercial and cultural facilities are actively being pursued in the construction industry, recently. Key examples of megaproject are Korea's development of the Incheon Free Economic Zone, the development of Roppongi Hills and Tokyo Midtown in Japan, the Euralille MXD, the development of Marina Bay in downtown Singapore, and the Atlanta urban renewal project in the USA. Meanwhile, mega-projects give rise to problems with various participating stockholders, large project costs, long-term project durations, complicated relationships between stockholders, and integration of the private and public development sectors.

A program management that pursues a mutually integrated and coordinated value, unlike the existing project management, is needed to solve these problems. Above all, the most important program management skill is a method of measuring and managing multiple risks. However, preceding risk related studies have been based on single projects and focused on measurement and evaluation of different risks, leading to limitations that prevent the results from being applied to mega-projects that are conducted over a long-term period.

Therefore, this study aims to develop a risk breakdown structure based on business processes and develop a threedimensional performance measurement method in connection to the structure, and ultimately provide a risk management process appropriate for large-scale projects.

\section{LITERATURE REVIEW}

\subsection{Business Processes}

According to Gartner(2005), BPM is everyday management activities that control the BP environment to 
increase efficiency of changes and duties in the BPM work environment, and is a structural approach method that continuously optimizes work and process using methodology, policies, measurement indexes, management activities and IT tools.

Therefore, BP focuses on operation of an effective work process. Process-focused evolution is necessary to actively counteract to the external environment and risks, and BPM is the key tool to materialize this evolution. This is why some studies that connect BPM and risks are recently being conducted, and a BP-based business management system is needed, especially focusing on large-scale projects.

\subsection{Risk Management}

The United States PMI (Project Management Institute) defines risk as something that threatens the project goal and various opportunities to reach the goal. It also presents risk management as a method of maximizing positive effects of a project through a process of risk categorization, analysis and counteraction, while simultaneously minimizing the results of elements that have a negative effect.

PMI largely divides risk into 1) known risks that can be distinguished and analyzed when planning a project, and 2) unknown risks that are managed as contingencies. Kim(2007) divides risks into 5 types - legal risks, market risks, financing risks, construction risks and stakeholder risks.

$\mathrm{Na}$ (2008) divides risks into 6 categories - systematical or administrative risks, economic or financial risks, sociocultural risks, stakeholder risks or risks of those related to stakeholders, technical or construction risks, and local or environmental risks.

\subsection{Performance Management}

Performance management is understanding and management of whether or not a business conducted by an individual or structure is being executed efficiently.

Domestic and international performance management methods largely consist of measuring mainly tangible performance such as financial performance and management performance. However, there is a lack of studies on performance management of programs that consist of multiple projects, and on risks that directly influence performance.

\section{Development of Performance Measurement Based on} Risk Breakdown Structure of Business Processes

\subsection{Direction of Development}

The direction of development was established by adding an evaluation method that can measure risk and performance based on the 7 BPM stages (process mapping, standardization, analysis/measurement, decision, cause excavation, improvements, verification).

As shown in Figure 1 below, risk factors and performance indicators were set between process mapping and standardization from the 7 BPM stages to add a stage that can connect the two. An evaluation methodology was also added to the existing analysis/ measurement stage.

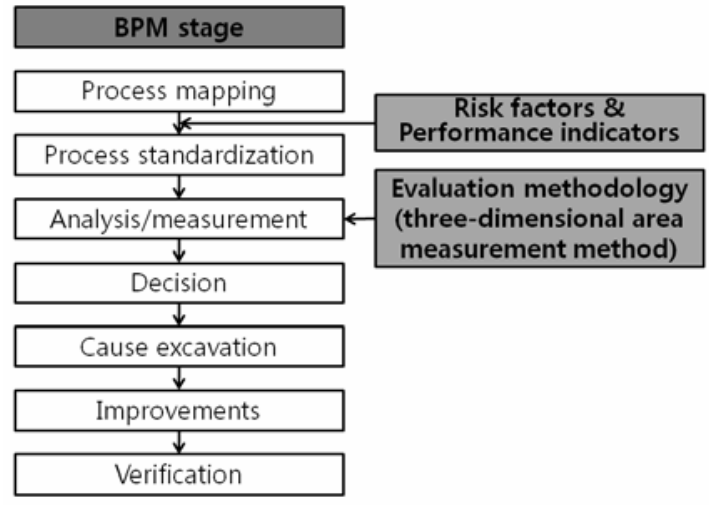

Fig. 1 Direction of Development

(BPM Stage + Risk \& Performance)

\subsection{BP and RBS Development}

A PM can consist of consecutive phases or activities to procure the final product or service.

Therefore, if the BP of the construction project is structured abiding by the AIA (The American Institute of Architects) standard, it can consist of project identification, pre-design, feasibility study, schematic design, design development, construction documents, procurement, construction, delivery and maintenance.

Based on preceding studies and case materials according to each stage, RBS eliminated similar factors and extracted 46 
factors (policy changes, delayed legal permission, uncertain deliberation, total cost increase, delayed project period, etc.).

This study aimed to extract a comprehensive performance score that can comprehensively analyze risk and performance of each BP stage based on the risk and performance measurement and life-cycle of each BP stage. Therefore, the 46 extracted risk factors were divided into 3 performance indicator groups through factor analysis. The 3 groups are first, the total cost group, including land cost, construction cost and financing cost, second, the schedule group, including construction duration, and lastly, the system/administration/subject group, including legal permission and stakeholders.

\subsection{Risk and Performance Measurement (RPM)}

Risk management can change according to the number and predicted value of risk factors at each BP stage. Each risk of each stage was measured based the Likert scale of 1 to 5 using the P-I matrix (probability-impact risk assessment matrix). The combined risk of each stage can also be calculated as the sum of each individual risk.

Performance measurement can be measured based on the 3 standards extracted through factor analysis - total cost, schedule and system/administration/stakeholders, and since qualitative and quantitative factors are mixed, a threedimensional area measurement method for the three factors was developed as shown in Figure 2 and used for measurement.

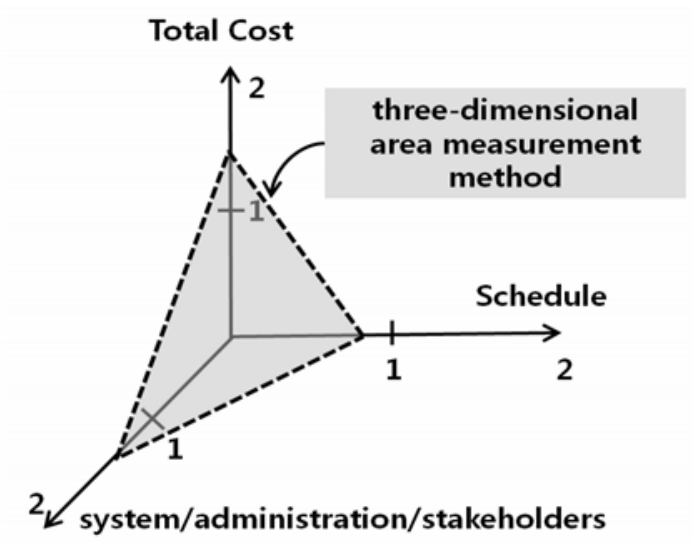

Fig. 2 three-dimensional area measurement method
Since the top value of each of the 3 factors is different the three-dimensional method first converts the values with 1 as the standard, and then considers total cost and schedule that has \pm values to convert the performance score of each factor with 2 as the highest score. Total cost and schedule were calculated quantitatively through performance considering plan, and the qualitative system/administration/stakeholders factor was measured using the Likert scale of 1 to 5 .

\subsection{Development of a BP-based RPM Process}

A risk breakdown structure based on business process and a related three-dimensional performance measurement method were developed based on the above. A risk management process appropriate for large-scale projects can be presented as shown below in Figure 3 .

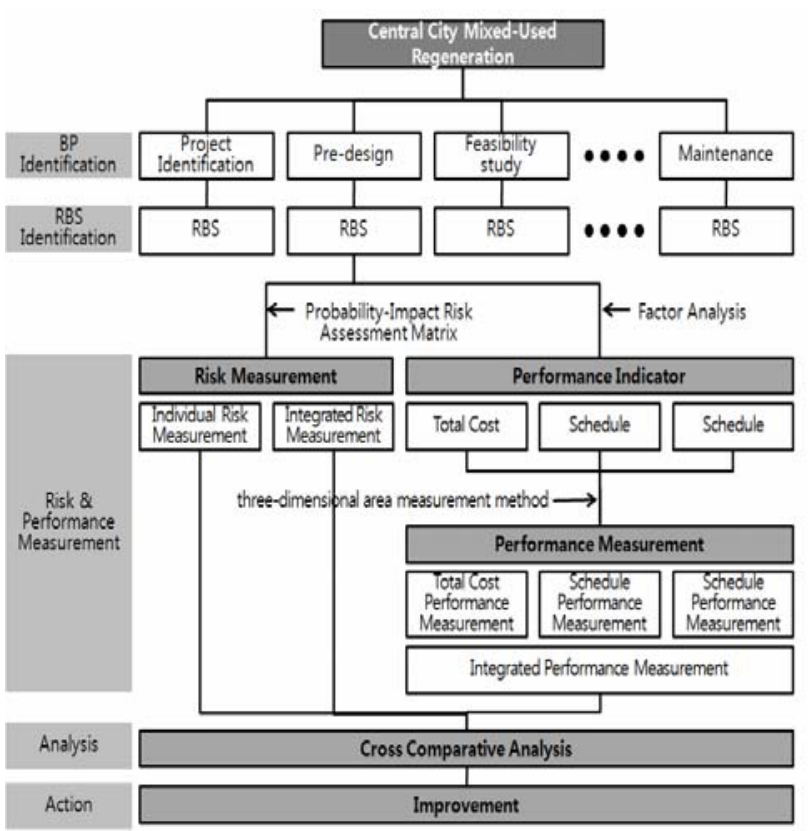

Fig. 3 BP-based RPM Process

\section{CONCLUSION}

Recently, many program level large-scale projects are being pursued both domestically and internationally. Since there projects have long-term durations, risk and performance management are most important.

Therefore, this study defined BP focusing on large-scale projects and presented 46 risk factors according to each stage. Then, performance was measured based on 46 risk 
factors, and a three-dimensional area measurement method was developed and applied to confirm comprehensive performance.

Based on the above, a process that connects BP with risk and performance was presented. The process manages risk and performance according to each stage of the comprehensive BP through a management system that focuses on each factor, and is expected to make fast and convenient management of the entire project process possible.

Future studies should focus on verification of the threedimensional measurement method and analysis of the correlation between risk and performance factors.

\section{ACKNOWLEDGEMENT}

This research was supported by a grant (07 Urban Renaissance B03) from High-Tech Urban Development Program funded by the Ministry of Land, Transport and Maritime Affairs of the Korean Government.

\section{REFERENCES}

[1] Abeysinghe, G. and Urand, D., 1999, "Why Use Enactable Mobels of Construction Process?”, Journal of Construction and Management, Vol.125, No.6, p.437.

[2] Flyvbjerg, B., Bruzelius, N., and Rothengather, W., Megaprojects and Risk; an Anatomy of Ambition, Cambridge University Press, Cambridge, UK, 2003

[3] Gartner(2005), Business Process Managene: Preparing for the Process-managed Organization, Gartner Research Report.

[4] Hyun, C., Son, M., Kim, Y., Kim, S.(2010) "Development of the Intelligent Program Management Information System (i-PgMIS) Framework for MegaProjects", ICSU 2011 Conference

[5] Hyun, C., Son, M., Kim, Y., Shin, S.(2010) "Development of a web-based cost and duration management system for mega-projects", ICCEPM 2010 Conference

[6] Kim, M. H. (2007) Analysis of the Risk Factors in the Real Estate Development Project. Housing and Urban Research, 50-67
[7] Kim, S. G., Park, K. Y., and Yu, Y. J. (2009) A development of risk Performance Index for Mega-project Performance Measurement in view of the integrated Cost/Schedule/Risk. Journal of Korea Institute of Construction Engineering and Management, 10 (1), 69-77 [8] Na, I. S., Kim, S. G., Ahn, K. H., Lee, S. K., Shim, G. E., and Park, K. Y. (2008) Risk Breakdown Structure and Risk Factor Dictionary in Mixed-use Mega Project. Journal of Architectural Institute of Korea, 24 (8), 225-232

[9] Park, K. Y. and Kim, S. G. (2009) A Development of Risk Identification Checklist for Stakeholder in Urban regeneration-Projects. Journal of Korea Institute of Construction Engineering and Management, 10 (4), 67-75

[10] PMI(Project Management Institute), Project Management Body of Knowledge, PMI, 2000

[11] Yu, Y. J. and Kim, S. G. (2008) A Study on the Mapping of Risk Factor with Performance Index in Urban Regeneration Project. 2008 Congress: Journal of Korea Institute of Construction Engineering and Management, 497-500

[12] Yun, S. H., “A case study of feasibility analysis and decision making method for the construction project development”, Architectural Institute of Korea, Vol. 19(10), pp. 75-82, 2003. 